\title{
Protestas populares de baja intensidad en la Asturias de posguerra
}

\author{
Ramón García Piñeiro
}

\section{RESUMEN}

El régimen franquista nació y fue sostenido para imponer la identidad ideológica dentro del

Movimiento y para reprimir cualquier forma de conflicto, ya fuera laboral o político. Hasta ahora

se ha venido sosteniendo que se alcanzó plenamente tal objetivo, al menos durante la década de los cuarenta, etapa en la que, excluida la actividad guerrillera, quedaron reducidas al mínimo las manifestaciones de resistencia colectiva o individual. Esta aparente resignación social ha sido subrayada con

perplejidad en más de una ocasión por los investigadores, dada la sólida ideologización y la demostrada combatividad de algunos sectores de la sociedad española. Certeramente se ha intentando relacionar la pasividad de los derrotados con la intensidad de la represión y el alarde de fuerzas del orden exhibido, aunque también se ha vinculado con las alteraciones demográficas experimentadas por la clase obrera e incluso con la política paternalista auspiciada por el ministro de Trabajo. Sin embargo, no se ha cuestionado la ya tópica concepción de la posguerra como una etapa de "paz social", imagen deliberadamente proyectada por un régimen concebido para ahogar y ocultar cualquier manifestación de disidencia. La utilización de nuevas fuentes pone al descubierto un variado repertorio de actitudes de rechazo y hostilidad política que, hasta el presente, han sido minusvalorados. 


\section{LA FIDELIDAD A LAS IDEAS COMO FORMA DE RESISTENCIA}

A los derrotados se les impuso que abjuraran de sus convicciones ideológicas y que renunciaran a sus lealtades políticas, las cuales no podían ser cultivadas ni en la más estricta intimidad familiar. Ante el incierto reto de integrar al desafecto en el Movimiento, las nuevas autoridades asumieron la prioridad de impedir cualquier manifestación política discordante, ya fuera en público o en privado. Sin embargo, a pesar del amedrantamiento general, no pudieron evitar que de forma aislada e inconexa surgieran chispazos de rebeldía popular, cuyo valor no es únicamente testimonial. Hubo personas, como Mercedes Joglar Villar, de Lastres, que esgrimieron sus principios con gallardía, evidenciando que no estaban dispuestas a renunciar a su ideología. En mayo de 1942 la autoridad gubernativa tuvo conocimiento de que esta mujer pregonaba en público «que era roja, que lo seguiría siendo y que, si la metían (por ello) en la cárcel, ya la sacarían". En la denuncia se añadía que, con sorna, se preguntaba si «esta es la España grande que se decia», al tiempo que calificaba la situación como vergonzosa porque «con lo que da Auxilio Social no se puede vivir". Con el mismo desparpajo, según la delegada local de la Sección Femenina, profería frases injuriosas contra el Régimen y «contra nuestro Generalísimo» 1.

Otros esgrimían los recuerdos del pasado, concretamente los servicios prestados a la causa republicana, como forma de resistencia. El zapatero ovetense Alberto Miguel Helguera reconoció ante un confidente policial que había «integrado la célebre columna que desde Alcalá de Henares envió sobre Oviedo Valentín González (a) El Campesino». Tras alardear después de «trabajar muy bien el Socorro Rojo Internacional y la propaganda", culminó sus indiscreciones remachando "que nos encontramos así porque no ha habido nadie entre nosotros que haya tenido dos cojones para pegar dos tiros a Franco, pero todavía rio es tarde» 2.

Más comprometedora fue la actitud de quienes mostraron en público que se mantenían fieles a las opciones políticas e ideologías proscritas. En Pola de Lena fue detenido en marzo de 1944 por cantar la Internacional Raimundo Duarte Lorenzo, que habia sido sargento del

1 El Comandante del Puesto de la Guardia Civil de Colunga, 25 de mayo de 1942. Archivo Histórico Provincial de Asturias. Sección Gobierno Civil (todos los documentos, excepto que se especifique un origen distinto, tienen la misma procedencia).

2 Parte del Servicio de Información Policial (en adelante SIP) núm. 120, 14 de mayo de 1947. 
"batallón Bolchevique núm. 236» 3 . Un año después, la Brigada de Información de la Policía denunció por «apología del marxismo» a Eloy Sainz de Baranda Alonso, ex maestro nacional que había sido "capitán rojo», quien, además, «tocaba en un instrumento de cuerda el Himno de Riego cantándolo a la vez con letra alusiva a curas, monjas y frailes». Este extremo no pudo ser confirmado por la Guardia Civil de Colombres, para quien se trataba de un rumor, pero sí admitió la Benemérita que el denunciado era una persona de «prestigio de tal ambiente -en referencia a los izquierdistas de la zona- dada su cultura y disimulo" 4 .

Hubo quien se limitó a corear alguna de las consignas prohibidas, aunque probablemente más como ejercicio de catarsis o expresión de un hondo malestar que con el propósito deliberado de plantear un desafío político. Así, Ángel Alonso García, que estaba conceptuado como apolíti$c o$, fue ingresado en la prisión del Coto y condenado a 15 días de arresto por proferir en un chigre de Gijón varios vivas a la República, rematando sus vítores con un sonoro "salud». Tan atrevido gesto debe interpretarse más como un desahogo que como una provocación política ${ }^{5}$. Esta circunstancia no ofrece duda en el caso de José Menéndez Rodríguez, un niño de once años que en 1940 tuvo la osadía de emitir un inequívoco "viva Rusia" aprovechando que el tranvía en el que volvía de las fiestas de San Agustín en Avilés se habia quedado momentáneamente sin fluido eléctrico. En esta ocasión el castigo gubernativo recayó sobre el padre, "de tendencia izquierdista", quien ya había sido multado con 500 pesetas «por desafecto" 6 . Más prudentes fueron los mineros del grupo Marianas, sito en las proximidades de Boo, aunque no por ello se libraron del ejemplarizante castigo. En febrero del mismo año rotularon las vagonetas con "vivas" a Rusia y a la UGT acompañados de "mueras" a Franco. Como no fueron descubiertos los autores de los anónimos rótulos, se les impuso a todos los trabajadores implicados en «la maniobra de los vagones" una multa de 35 pesetas 7.

3 Puesto de Pola de Lena, 8 de septiembre de 1949. Delegación de Orden Público de Asturias, 3 de octubre de 1949. El Gobernador Civil, 10 de mayo de 1952.

4 Brigada de Información, Dirección General de Seguridad (en adelante DGS), 18 de febrero de 1945. Gobernador Civil al Comandante del Puesto de Colombres, 5 de marzo de 1945. El Comandante del Puesto, 12 de marzo de 1945. El Gobernador Civil impuso al denunciado la prohibición absoluta de impartir clases particulares.

5 Teniente Coronel Delegado de Orden Público de Gijón, 27 de septiembre de 1941.

6 Puesto de Villalegre, 30 de agosto de 1940.

7 Puesto de Boo, 6 de febrero de 1941. 
Las tensiones vividas y el desasosiego causado por el ambiente político provocaron algunas reacciones esquizofrénicas en las que se invertian los términos del síndrome de Estocolmo, sobre todo cuando intervenía el alcohol en dosis mal digeridas. Un caso de dominador que se siente irresistiblemente fascinado por las victimas lo brinda Joaquín Solana Rambaud, odontólogo gijonés que fue detenido por rematar en un bar de Salas una áspera andanada de «frases vejatorias e injuriosas contra el jefe de Estado" con encendidos vítores a Negrín y a Rusia. El ofuscado dentista, al que se le abrió un expediente depurador en su colegio profesional, estaba conceptuado como "adicto al Régimen» y era "falangista de los llamados Camisa Vieja" ${ }^{8}$. El vértigo de pronunciar en público expresiones prohibidas también lo sintió el vecino de Turón Ángel Álvarez García, falangista, ex divisionario y delegado local del Seguro de Enfermedad en Pola de Lena. El 8 de abril de 1949, también en estado de embriaguez, desfiló por la calle más céntrica de Moreda vitoreando a la República. Cuando fue conminado a que se callara dejó constancia de sangre fría y sagacidad, a pesar del alcohol ingerido, al manifestar que pretendia propiciar que alguien coreara sus vitores para poner al descubierto emboscados enemigos del Régimen ${ }^{9}$.

\section{CRITICAS AL RÉGIMEN}

Más frecuentes fueron las críticas al Régimen, las cuales se intensificaban cada vez que se percibía algún síntoma de debilidad. En un informe remitido a la Dirección General de Seguridad en julio de 1943 se reconocía la creciente osadía de "los elementos desafectos", quienes "van perdiendo su posición latente». Coincidiendo con los éxitos militares de los aliados -concluía el informe- «se observa una mayor animación en sus tertulias y van en aumento los actos individuales en los que, de un modo u otro, se manifiestan públicamente contra el Régimen" 10. Así, tenemos constancia de que se pronunciaron en estos términos, entre otros, el sotrondino Manuel Rodríguez Cueto, el vecino de EI Entrego Ángel Montes Álvarez, José Calvo Martínez, maestro de Ovín, y el gijonés José

8 Puesto de Salas, 31 de enero de 1941. Gobernador Civil, 4 de febrero de 1941. Comisaría de Investigación y Vigilancia de Oviedo, 11 de febrero de 1941. Colegio Oficial de Odontólogos de la XII Región, 29 de enero de 1944. Gobierno Civil, 4 y 11 de febrero de 1944. Puesto de la Calzada, 7 de febrero de 1944.

9 El Gobernador Civil, 30 de abril de 1949.

10 Boletín decenal núm. 19, SIP, Oviedo, 10 de julio de 1943. 
García Alonso, apodado «El Bigotes» «por su admiración hacia Stalin" 11 . Sin que ello se pudiera interpretar como un atenuante, no se ocultaba que, a veces, los denuestos dirigidos al Régimen y los vituperios lanzados contra la Guardia Civil, el Ejército, la Falange o el mismo Franco se realizaban "en evidente estado de embriaguez» 12.

Con frecuencia la hostilidad popular se dirigía hacia las autoridades locales, ya fuera por divergencias políticas o por rencillas personales. En mayo de 1942 el alcalde de Riosa reclamó del gobernador civil una dura sanción para José Álvarez Muñiz, conocido con el sobrenombre de El Cachorro, por comparecer ante él «blasfemando escandalosamente y profiriendo palabras gravemente injuriosas y soeces contra la autoridad del Alcalde y de las instituciones del Glorioso Movimiento Nacional". El altercado, presenciado por el jefe local de Falange, fue confirmado por la Guardia Civil, la cual caracterizó a El Cachorro como «persona desobediente a las órdenes de la Autoridad y simpatizante izquierdista" 13. Poco después, en julio, recayó la misma acusación contra Recaredo Arias García, de las Vegas (Teverga). Al parecer, cuando se le acercó una señorita con la intención de colocarle en la solapa una banderita de la Cruz Roja "de parte del alcalde», prorrumpió en todo tipo de improperios "y palabras ofensivas" contra la autoridad local ${ }^{14}$. Menosprecios de este tipo también tuvieron como destinatario a personas e instituciones representativas del Movimiento. En el mes de enero de 1944, por ejemplo, fue multada Fermina Álvarez Fernández, de Proaza, por hacer caso omiso de forma reiterada a los requerimientos de la Delegación Local de Sindicatos. Según la denuncia formulada contra ella, se negaba a acudir a los llamamientos «alegando que no quería saber nada de la organización sindical» y que cada vez que asistía a las convocatorias que le hacian «no tenían resultado práctico alguno» 15.

Estas reacciones siempre recibian una respuesta contundente, pero provocaban una irritación especial cuando venían acompañadas de actos

11 Puesto de Sotrondio, 26 de mayo de 1941. Parte del SIP núm. 266 de 24 de septiembre de 1945 y núm. 207 de 26 de julio de 1947. El Jefe Provincial del Movimiento, 8 de enero de 1947.

12 Así se precisó en la denuncia formulada contra Heliodoro Álvarez Álvarez, futbolista del Bierzo afincado en Oviedo, o Alfredo Alonso Garcia, electricista del ferrocarril Vasco-Asturiano con residencia en Grado. Puesto de Oviedo, 24 de julio de 1945. Puesto de Grado, 4 de marzo de 1941.

13 Ayuntamiento de Riosa, 11 de mayo de 1942. Puesto de Foz, 22 de mayo de 1942.

14 Ayuntamiento de Teverga, 10 de julio de 1942. Puesto de Entrago, 12 de agosto de 1942.

15 Jefatura Provincial del Movimiento, 28 de enero de 1944. Gobierno Civil, 31 de enero de 1944. 
o expresiones soeces. En junio de 1945, el Servicio de Información Policial imputó a José García Morán, vecino de Gijón y representante de DDT, que habia exhibido en el ferrocarril Vasco-Asturiano unos folletos en los que «aparecian escenas deshonestas como la de un jefe del Frente de Juventudes practicando sodomía con una flecha y otras de la sección femenina». También que había mostrado una composición fotográfica en la que aparecían Franco, Churchill y Stalin bajo el rótulo "ya somos amigos todos". Dada la gravedad de las acusaciones intervino en su esclarecimiento el propio gobernador militar quien, además de no poder confirmar los hechos, precisó que el denunciado era "persona de orden y pertenece a Acción Católica» 16. Similar estupor produjo la reacción de Samuel Jiménez Álvarez, médico madrileño que, en Cangas de Narcea, se dirigió a un grupo de vecinos interesándose por el diputado de la zona. Según el delegado local de Investigación e Información de FET y de las JONS, tras precisarle los interpelados que ya no había diputados sino consejeros nacionales y procuradores en cortes, el galeno les replicó en estos términos: «ahora los untan con vaselina, luego les dan por el culo y después les extienden un certificado de que prestaron grandes servicios a la Patria» 17.

Ahora bien, no todos los actos individuales de hostilidad política fueron protagonizados por el llamado "elemento rojo", en referencia a las personas de antecedentes izquierdistas. Por no saludar a la romana cuando sonaban los acordes del "Himno Nacional» fue detenida la farmacéutica ovetense, aunque de origen peruano, Blanca Rodríguez Vela, a la que de poco sirvió presentar en su descargo «una brillante ejecutoria de patriotismo ejemplar y probado afecto al Estado Nacionalsindicalista". La falta de respeto la cometió en septiembre de 1942 durante la procesión que se celebró en Oviedo para restituir las reliquias a la Cámara Santa, en la que participó Francisco Franco. En su presencia se negó a levantar el brazo y cuando fue conminada por un agente para que saludara, "como estaba haciendo todo el mundo", se limitó a replicar despectiva que «ella no tenía la culpa de que todos fueran bobos". Una vez sancionada, suplicó que le fuera condonada la multa por su condición de antigua afiliada a FET y de las JONS y porque, previamente, "había sido zarandeada en forma desconsiderada" por un policía cuando intentó cruzar la calle ${ }^{18}$. A

16 Partes del SIP núm. 180 y 181 de 2 y 4 de julio de 1945. El General Gobernador Militar, 3 de agosto de 1945.

17 El jefe provincial del Movimiento, 4 de agosto de 1944.

18 Diligencias del 5 de septiembre de 1942. Instancia de 17 de septiembre de 1942. Cuerpo General de Policía de Oviedo, 2 de octubre de 1942. 
pesar de los riesgos que entrañaba, también se sintieron tentados a traslucir su descontento de manera similar algunos servidores del Movimiento que perdieron los cargos, y con ellos la confianza política, por rivalidades internas o por haber perpetrado flagrantes irregularidades en su gestión. Parece ser que por este motivo, José Fernández Colau fue relevado de sus funciones como delegado local de Falange en Cangas de Narcea. En respuesta, según un confidente no identificado, se dedicó en 1943 a propalar noticias captadas «en radios aliadas" y a realizar «manifestaciones contrarias al nuevo Estado", extremo éste que no pudo ser confirmado por la Guardia Civil ${ }^{19}$.

\section{DIFUSIÓN DE BULOS Y NOTICIAS TENDENCIOSAS}

Por interpretar que el destino político de España dependía de su desenlace, muchos españoles siguieron con cautelosa expectación los avatares de la $11 .{ }^{2}$ Guerra Mundial. Los vencedores estaban convencidos de que el triunfo del Eje respaldaría su posición, mientras que, sin tanto fundamento, los derrotados depositaron sus últimas esperanzas en la causa aliada. Por ello, las autoridades franquistas procuraron silenciar todo comentario y, sobre todo, consideraron un acto de hostilidad las muestras de simpatía hacia los aliados. Este tipo de manifestaciones fueron perseguidas con especial ahínco entre junio de 1940 y octubre de 1943, periodo en el cual España aportó hombres y recursos a la causa del Eje aunque oficialmente se declaró «no beligerante". En esta etapa, tuvo que comparecer ante el Auditor de Guerra de Asturias el vecino de Villaviciosa Manuel Miranda Obaya, a quien se le instruyó atestado en octubre de 1940 por cinjurias a países extranjeros" tras asegurar que de nada serviría el pacto tripartito entre Alemania, Italia y Japón ante la superioridad militar de EE.UU. y profetizar el "regreso del periodo rojo a España» 20. También por «intentar convencer a sus vecinos" de que Inglaterra vencería a Alemania manejando el argumento de que «el segundo jefe alemán ya se había fugado para Inglaterra", fue puesta a disposición del gobernador militar la somedana Rosario Arnaldo López, pero en este caso los cargos eran mucho más graves. Según el atestado, además de sus comentarios sobre el desarrollo de la guerra, "se dedica constantemente a proferir palabras injuriosas contra el Gobierno y nuestro glorioso Caudillo, del que dice es un

19 El Comandante del puesto de Cangas de Narcea al Gobernador Civil, 12 de julio de 1943.

20 Puesto de Villaviciosa, 9 de octubre de 1940. 
ladrón, criminal y bandido que no se dedica nada más que a robar matando a la gente de hambre y que va a tener que preparar las maletas para huir de España» 21.

Ante la imposibilidad de silenciar las opiniones expresadas en un ambiente íntimo y familiar, las autoridades persiguieron las reuniones domiciliarias ante un aparato de radio en las que se presumiera la presencia de "elementos peligrosos para la causa Nacional". Cuando había indicios de que se emitían comentarios sobre la marcha de la guerra, si las preferencias de los contertulios se decantaban del bando aliado, estos se tipificaban como «bulos tendenciosos". Por ello fue denunciado en 1944 Santiago Unzueta Legorburo, vecino de Sotrondio, precisándose que, dada la proximidad de su domicilio al pozo San Mamés, participaban en la tertulia mineros que redimían pena en la Colonia Penitenciaria 22. También sứrían el acoso de las autoridades quienes mostraban públicamente sus preferencias por las informaciones que de la guerra mundial proporcionaban los aliados, aunque fuera en una conversación privada y de forma discreta. En Villaviciosa, por ejemplo, fue denunciado el médico Guillermo Muñiz González «por escuchar con más ahínco los partes de Inglaterra, Moscú y Norteamérica, cosa ésta que ha demostrado en un café de esta localidad". Por ello le fue abierto expediente en su colegio profesional ${ }^{23}$. Lógicamente, se adoptaban medidas más contundentes cuando las audiciones daban pábulo a comentarios públicos, especialmente si las valoraciones se realizaban ante un colectivo tan temido por el Régimen como los mineros. En octubre de 1943, Mauro Martínez González fue deportado de San Cebrián de Mudá y confinado en Mieres, donde había residido hasta julio de 1936, "por hacer manifestaciones públicas en presencia de los demás trabajadores de las minas a favor del triunfo de los anglonorteamericanos y bolcheviques" 24 .

Ahora bien, la vigilancia se extremaba en todos los establecimientos públicos que disponían de aparato de radio, especialmente cuando eran frecuentados por «individuos indeseables y rojos». En estos casos, las audiciones radiofónicas se interpretaban como «actos de conspiración contra el Régimen" y, cuando las denuncias procedían de particulares o de la Delegación Provincial de Información e Investigación de Falange, se

21 Puesto de Somiedo, 27 de mayo de 1941.

22 Puesto de Sotrondio, 12 de agosto de 1941.

23 Puesto de Villaviciosa, 9 de diciembre de 1941. DGS, 27 de noviembre de 1941.

24 Gobierno Civil de la Provincia de Palencia, 15 de octubre de 1943. Inspección de Mieres del Cuerpo General de Policía, 17 de diciembre de 1943. 
adornaban con graves imputaciones para provocar la intervención fulminante de las autoridades. Con este propósito, en marzo de 1943 se comunicó que en un bar de Trespando (Siero), regentado por Josefa Villanueva, se había celebrado un banquete hasta altas horas de la madrugada para celebrar «la evacuación de Kharkov por la tropa alemana y su ocupación por los rusos", extremo desmentido por la Guardia Civil. En la denuncia se añadía que el establecimiento era "el lugar de reunión de los chekistas (en el que) se fraguó la quema de la Iglesia de Trespando durante la etapa roja» 25 .

En todo caso, las expresiones de «aliadofilia» se incrementaron a partir de 1943, animadas por la marcha de la contienda y coincidiendo con el retorno de España a la neutralidad. En enero de 1944 se puso en conocimiento de la autoridad que todas las tardes se congregaban centenares de personas ante el consulado inglés en Gijón «para recoger el parte de guerra o boletín de información y demás propaganda relacionada con la contienda internacional», puntualizándose que la larga cola "está formada en su mayor parte por mujeres y hombres de la clase obrera y entre ellos se encuentran conocidos extremistas" 26. También se denunció que en la tienda de Vicente Rojo Rodríguez, sita en El Entrego, se reunía con frecuencia para oír las emisiones de Moscú «un cierto número de individuos de marcados antecedentes extremistas", lo cual fue desmentido por el gobernador militar 27 . Dada la incertidumbre política, ni siquiera se toleraban las audiciones públicas en las que únicamente participaran personas de inequívoca lealtad al Régimen. En noviembre de 1943 se precintó el aparato de radio del café del Carmen, en Cangas de Narcea, punto de encuentro de «autoridades locales y personas afectas", para evitar que se «fomentaran bulos con las consiguientes alarmas» 28.

La expectación popular por la marcha de la guerra alcanzó su cénit en 1945 , una vez que se despejaron las dudas sobre el desenlace de la contienda. Ante el «latente estado de intranquilidad pública», reconocido por las autoridades, se reforzó la vigilancia y se endurecieron las medidas represivas. En el mes de junio fueron detenidos y multados Cirilo Fernández, Ramón Álvarez-Buylla Muñiz, Mercedes Arias Alonso y Antipas

25 Delegación Provincial de Investigación e Información, 30 de marzo de 1943. Jefatura Provincial de Asturias de FET y de las JONS, 30 de marzo de 1943. Puesto de la Guardia Civil de Mieres, 17 de abril de 1943.

26 Comisaría del Cuerpo General de Policía de Gijón, 27 de enero de 1944.

27 Parte del SIP, núm. 170, 22 de junio de 1945. El General Gobernador Militar, 31 de julio de 1945.

28 Jefatura Provincial del Movimiento, 17 de noviembre de 1943. 
Martínez Gutiérrez, todos ellos vecinos de Avilés, por "difundir y comentar entre sus amigos las noticias de radio que dan las emisiones aliadas, las cuales captan con aparatos receptores de radio de su propiedad". Los mismos correctivos se aplicaron en el mes de agosto a Maximino Suárez Suárez, de Soto (Aller), por «propalar noticias de carácter tendencioso y derrotista contra la organización del Estado" 29 . Ahora bien, el creciente nerviosismo de los grupos más directamente comprometidos con el Régimen quedó de manifiesto en un incidente ocurrido en Avilés: el 20 de agosto de 1945 los escaparates de una sucursal de la Casa Singer que habian sido adornados con banderas inglesas, americanas y españolas para festejar el fin de la guerra aparecieron pintados de negro con el expresivo rótulo de "Arriba España", acto atribuido a "exaltados falangistas" y censurado por «las personas de orden» al colegir que «pueden ocasionar ciertos trastornos a la política exterior del Gobierno" 30.

Durante el segundo lustro de la década y mientras se mantuvo la incertidumbre sobre la actitud de los vencedores hacia España, permanecieron alerta los servicios policiales para detectar a radioyentes disconformes y evitar la propalación de «noticias tendenciosas y derrotistas". Por este motivo fue denunciada Teresa García Castañón, farmacéutica de Cabañaquinta, a la que también se le imputó haber pronosticado que le quedaba poco tiempo «al Gobierno fascista», que a Franco «pronto le darán la patada de Charlot" y que, como consecuencia de ello, todos volverían a comer pan blanco. Los servicios de información policial admitieron que la acusación no pudo ser comprobada "por falta de civismo" al tiempo que la Guardia Civil tampoco pudo corroborarla al desdecirse la única delatora, Sabina González García. No obstante, no cuestionaron su veracidad por sus antecedentes socialistas -su padre José García «presentó candidatura para Diputado durante el Frente Popular»-, por estar clasificada como desafecta y por haber emitido comentarios despectivos hacia el Jefe del Estado coincidiendo con su visita a Asturias en mayo de $1946^{31}$. En ocasiones, el celo y la suspicacia policial alcanzaban extremos delirantes. En junio de 1947 se dio crédito a la confidencia de que en un bar de Corvera se concentraban los vecinos para oír las emisiones de radios extranjeras y «hacer campaña tendenciosa contra el actual Régi-

29 El Gobernador Civil al comandante del puesto de Avilés, 30 de junio de 1945. Puesto de Moreda, 22 de agośto de 1945. Puesto de Cabañaquinta, 25 de agosto de 1945. Gobierno Civil, 22 de agosto de 1945.

30 Servicio de Información de la DGS, Oviedo, 28 de agosto de 1945.

31 Parte del SIP núm. 140, 21 de mayo de 1947. El Coronel Jefe del $41 .^{2}$ Tercio de la Guardia Civil, 12 de junio de 1947. 
men español». En el parte informativo se trajo a colación que en el citado barrio, poblado por personas mayoritariamente hostiles, prestaba sus servicios un mozo de labranza «que oculta el lugar del pueblo (sic), se muestra muy reservado y lee con avidez las noticias de los periódicos". Por todo ello se concluía que era "un elemento sospechoso" 32.

Capítulo aparte merece la consideración de las denuncias falsas, presentadas por los motivos más diversos. Generalmente eran formuladas por personas que, prevaliéndose de su aquiescencia con el Régimen y del descrédito de los denunciados por su condición de desafectos, pretendían obtener algún beneficio material $o$, simplemente, resarcirse de alguna afrenta personal. En julio de 1941, un grupo de falangistas y ex cautivos de Limanes presentaron una denuncia contra varios vecinos que, a su vez, eran familiares de los delatores. En ella los acusaron de concentrarse en la vivienda de José Fanjul Álvarez para persuadir a los obreros que se dirigían al trabajo de que «el triunfo es de los rusos y no de los alemanes», por lo que «pronto estarán en España para acabar con los canallas de los falangistas". Dado que los acusados eran solventes, concluyeron el escrito reclamando que se impusiera una multa de 2.000 pesetas a cada uno. Trasladada la instancia a la Guardia Civil, ésta desveló que, a pesar de las diferencias ideológicas, las partes siempre habían mantenido muy buenas relaciones, hasta el punto de que los denunciantes habian intercedido en varias ocasiones a favor de los denunciados, de tendencias izquierdistas aunque «sin llegar a tener una actuación destacada». Sin embargo, la armonía se quebró con motivo de una herencia en un caso, "que dio lugar a varios altercados graves", y, en otro caso, por la venta de la hierba de un prado, "que dio origen a un conato de agresión». En la denuncia habían colaborado los alcaldes de barrio de Limanes y Pando, mediante el engaño, ya que se les había asegurado que únicamente se pretendía poner en conocimiento de las autoridades sus antecedentes izquierdistas cuando el móvil no era otro que la animosidad personal 33 .

En otras ocasiones no queda constancia del motivo concreto de la delación, pero en todo caso se percibe la presencia de una antigua rencilla que se reviste ahora de contenido político para hacer más daño. En mayo de 1945, por ejemplo, se denunció que en un domicilio de Pola de Lena se reunían varias personas para escuchar la radio y «fomentar un ambiente desfavorable al Régimen", por lo que era conocido entre el vecin-

32 Parte del SIP núm. 158, 10 de junio de 1947.

33 Instancia de 21 de julio de 1941. Puesto de Colloto, 12 de agosto de 1941. 
dario como «Radio mortal». Para agravar la imputación se añadió que «durante el dominio rojo era lugar de reunión de los elementos más extremistas y significados en saqueos y en cometer toda clase de tropelías", concluyéndose que uno de los residentes en la vivienda, Baldomero Tuñón Menéndez, se consideraba «sospechoso de desplegar alguna actividad político social» por el mero hecho de viajar con frecuencia. Tras la investigación realizada por la Jefatura de Orden Público, se comprobó primero que los denunciados carecían de aparato de radio y que la hermana de Baldomero era conocida en tono humorístico como «radio portal», no «mortal», «por lo enterada que la consideran de toda clase de noticias, estén o no relacionadas con la marcha de la guerra». Por último se atribuyeron los "sospechosos" movimientos de Baldomero y la presencia de vecinos en el domicilio con un grave accidente sufrido por su madre ${ }^{34}$.

Entre los «adictos" al Régimen, el procedimiento de la denuncia también fue utilizado como arma política para neutralizar a posibles competidores en la carrera por los cargos. En enero de 1943 se puso en conocimiento de la autoridad que en la fonda "La Moderna" de San Martín de Teverga, regentada por quien había ocupado hasta fecha reciente la alcaldía y por el jefe local de Falange, se congregaban diariamente "elementos simpatizantes de los aliados" para escuchar y comentar en público las emisiones de Radio Londres. Dados los antecedentes de los denunciados y en virtud de sus propias indagaciones, la Guardia Civil calificó de tendenciosa la imputación y la atribuyó al deseo de «derrotar políticamente a esta familia con miras a ocupar alguna otra persona los cargos de delegado sindical de esta localidad que ejerce Don José Ramón Riego Fernández y el de jefe de Falange que desempeña el ya indicado Don Gonzalo Blanco Díaz, a parte de hallarse vacante en la actualidad el de Alcalde Presidente de este Ayuntamiento" 35 .

En todo caso, el cúmulo de denuncias presentadas, ya fueran ciertas o falsas, además de reflejar el espíritu revanchista y la degradación moral de sus promotores, desvelan también el ambiente de incertidumbre y tensión en que se vivía. En junio de 1943, por ejemplo, el Servicio de Información policial aseguró que Jesús Fernández había salido a la calle "excitando al vecindario contra la Guardia Civil y Falange" al interpretar el inesperado ulular de la sirena de la fábrica de cementos de Tudela Ve-

34 Parte del SIP, núm. 147, 30 de mayo de 1945. Jefatura de Orden Público de Asturias, 18 de junio de 1945.

35 El Comandante del Puesto de Entrago, 2 de febrero de 1943. 
guín como una inequívoca señal de que se estaba produciendo un desembarco inglés. En realidad, Jesús Fernández Granda había sido detenido por augurar en el domicilio de Amancio Fernández Fanjul el triunfo de los aliados, la restauración de un gobierno frentepopulista, las inmediatas represalias contra "los elementos de orden» y la pronta huida de Franco, «para lo cual ya tenía preparada la maleta». Después de realizadas estas manifestaciones, pero antes de la detención, el domicilio fue pasto de las llamas, provocando que saltara la sirena de la fábrica y la subsiguiente movilización del vecindario. Con estas coincidencias la imaginación popular, muy excitada por las tensiones del momento, fabricó su propio relato entretejiendo realidades, posibilidades y, en algunos casos, anhelos ${ }^{36}$.

\section{LA ESPERANZA DE LA SEGUNDA VUELTA}

Estas reacciones ponen de manifiesto que, durante la década de los cuarenta, ni los derrotados ni los vencedores descartaron la posibilidad de que se produjera un brusco vuelco político. A pesar del inequívoco desenlace de la guerra civil española, las expectativas para los vencidos se reabrieron con el estallido, algo más tarde de lo esperado, de la contienda internacional. Antes de que este pulso bélico comenzara a decantarse por uno de los bandos en liza, no pocos desafectos se atrevieron a pronosticar un inminente e inevitable derrumbe del Régimen. Esta convicción la expresó con rotundidad en 1941 Magencio López Saavedra, vecino de Oviedo, a quien no le cabía duda de que pronto podría él realizar «la limpieza de España (porque) gobernarán mis camaradas". Según la denuncia, este chatarrero natural de Lugo, después de vaticinar el triunfo militar de Inglaterra "porque siempre había sido el ama", injurió al jefe del Estado y acusó a los falangistas de perpetrar los robos, vestidos de paisanos, que luego se atribuian a los huidos por los montes 37.

En este mismo año fueron denunciadas en Avilés por similares motivos Teresa Fernández Tolivar y Serafina Alonso, popularmente conocida con el sobrenombre de «La Remega». De ambas se destacaba que habían convivido con personas sentenciadas y ejecutadas por un tribunal militar. La citada en primer lugar realizaba con frecuencia «manifestaciones

36 Parte del SIP, núm. 126, 16 de junio de 1943. Brigada de Información Policial, 28 de junio de 1943.

37 Secretaría de Orden Público, 17 de enero de 1941. 
de hostilidad al actual Régimen» y particularizaba su odio en el «camarada Anselmo Pérez Prieto y su esposa", a quienes identificaba con las nuevas autoridades. A «La Remega», que "había sido amante del comandante del batalión Pablo Iglesias", se le atribuyó el siguiente comentario: «ha sido una lastima que los rojos no hubiesen paseado a todos los derechistas, pero como cambie la situación no va a quedar uno con cabeza». En ambos casos se reclamaba que, al menos, fueran desterradas de la localidad 38. En 1942 elevó su lamento desde Lastres «la infeliz camarada Josefina Manso Covián, hermana del mártir Servando Manso Covián, asesinado por los rojos". Se quejaba ésta de que era acosada diariamente por Carmen Rodríguez Victorero, "de significadísima familia roja». La Guardia Civil de Colunga confirmó que la denunciada amenazaba a la falangista con "machacarle la cabeza», al tiempo que la llamaba "puta, rastrera y desgraciada». Incluso, según la Benemérita, se habia atrevido a acorralarla en una carnicería del pueblo para decirle que «el coco del fascismo ya se os acabó" y remachar, mientras levantaba el puño, que «ahora somos todos así». La Jefatura local de Lastres de FET y de las JONS reclamó que se "cortara de forma radical esta clase de abusos que a diario estamos presenciando", ya que de lo contrario "causarían un efecto de desmoralización que no tendría fácil remedio" 39.

Como es lógico, el ánimo de revancha anidó sobre todo en quienes más habían sufrido los efectos de la represión. La ciega confianza de la vecina de Somiedo Rosario Arnaldo López en que se implantaría en España un régimen comunista estaba vinculada al deseo de hacer pagar a sus vecinos "de ideal derechista» la muerte de su hijo 40 . El mismo propósito de desquite se atribuyó a Bernardo García García, de Coañana (Quirós), quien, al parecer, en octubre de 1943 le recordó al jefe local de Falange que ya se encargaría de resarcirse de todos los agravios «cuando esto cambie». El amenazado no omitió consignar que «el expresado individuo ha sido personalmente detenido por mí en la cueva de una peña en compañía de otros tres elementos marxistas huidos después de la liberación de esta provincia» 41 . Los rencores, aunque reprimidos, no se amortiguaron con el paso de los años. A pesar del tiempo transcurrido, el resentimiento seguía vivo en José Menéndez Riera, quien fue denuncia-

38 Jefatura Provincial del Movimiento, 11 de junio y 2 de septiembre de 1941. Puesto de Avilés, 2 de septiembre de 1941.

39 Puesto de Colunga, 27 de junio de 1942. Jefatura Local de Lastres, 15 de junio de 1942.

40 El Puesto de Somiedo, 27 de mayo de 1941.

41 Jefatura Provincial de Asturias, 6 de octubre de 1943. Puesto de Bárzana, 20 de octubre de 1943. 
do en 1949 por «amenazar con represalias para cuando sus compañeros liberen a España del yugo fascista» 42.

Estas amenazas, en ocasiones, tenían un carácter defensivo, ya fuera para mitigar la represión o, al menos, para sembrar la duda entre sus ejecutores. En el mes de julio de 1941 dos vecinas de La Felguera le reprocharon de forma despectiva a Manuel Hevia Nieto, jefe local de Información e Investigación de Falange, que hubiera emitido un informe desaconsejando la libertad condicional de Julián Crespo, esposo de una de ellas. Después se encararon con la madre del falangista, a quien le recordaron en tono amenazante que «el régimen no será siempre el mismo" 43. En el verano de 1944 fueron denunciados por motivos similares Ramón Toral Rosales y José Hevia Pérez, «destacados comunistas» de Villaviciosa. Al primero, «individuo de mala prosapia, marxista puro y hablador», se le imputaban comentarios intimidatorios dirigidos contra "falangistas, guardias civiles y municipales de la villa». Con la misma intención el segundo aseguraba que «cuando cambie el actual Régimen será cosa de días el exterminar a los elementos que hoy fanfarronean de mandamás" 44 . La incertidumbre existente y la reiteración de reacciones de este tipo sembraron la duda entre algunos franquistas, los cuales no rompieron todos los contactos con sus adversarios políticos. En 1945 fue denunciada la vecina de Pelúgano Mercedes Montes Fernández, «viuda de un extremista fusilado y que tiene dos hijos confinados fuera de la Provincia», por realizar las siguientes declaraciones: «ahora los de derechas no hacen más que festejarme para que los salve el día de mañana, pero están arreglados». También fue acusada de proferir «manifestaciones veladas y amenazas encubiertas contra la actual situación" y de dar cobijo en su domicilio a "elementos desafectos peligrosos" como Bienvenido Ordóñez González, su hermano Restituto, Amador Pérez González y Salvador Díaz ${ }^{45}$.

Las advertencias de este tipo aumentaron con los avances aliados en los frentes de guerra. El deseo de revancha personal y desquite político queda patente, por ejemplo, en las manifestaciones realizadas en 1945 por Elías Mori Canteli, de Infiesto, Faustino Secades, de Bello, y Fernando González, maletero de la estación del Norte conocido por el sobre-

42 Carta de Valentín Díaz, 19 de marzo de 1949. Cuerpo General de Policía, Jefatura de Oviedo, 5 de abril de 1949.

43 R. Arias de Velasco, jefe provincial del Movimiento, 31 de julio de 1941. Puesto de La Felguera, 9 de agosto de 1941.

44 Parte del SIP núm. 193, 11 de julio de 1944. Puesto de Villaviciosa, 24 de agosto de 1944.

45 Parte del SIP núm. 205, 24 de julio de 1945, y núm. 300, 15 de noviembre de 1945. 
nombre de «El Mariposo». Al primero se le acusaba de amenazar «con represalias cuando vinieran los suyos" a todas las "personas de orden" y, concretamente, de «haber prometido» a María González Cobián que le quemaría su casa. El segundo fue denunciado por haberle recordado al ex divisionario Maximino Rozada Rodríguez que iba a pagar un alto precio por haber participado en la División Azul, toda vez que «pronto tendría que ir a Rusia a reconstruir lo que había destruido la División". Y al último de los citados, que había sido «jefe de la organización juvenil Pioneros rojos", se le atribuia que intimidaba a muchas personas asegurándoles que "el día que lleguen los de él les dará muerte mediante el paseo" 46. Otro ex divisionario, Manuel Fernández Gutiérrez, vecino de Muñón Fondero (Lena), fue amenazado en el mes de julio en parecidos términos. Según su propio testimonio, cuando se dirigía al ayuntamiento le salió al paso Aurora «la Doncella» espetándole que «muy pronto le vería colgado por haber ido voluntario a Rusia», lo cual motivó que "la gente que se hallaba en las inmediaciones participara con muy buen gusto algunas de ellas y otras no" 47 .

No fue intrecuente, como ya hemos visto, que este tipo de denuncias fueran utilizadas de forma torticera. El falangista avilesino Marino Rodríguez Gutiérrez se dirigió en 1942 al Gobierno Civil para informar del contenido de una conversación sostenida por Benito Prendes García y Manuel García Fernández. En su escrito manifestó que, al jurar el primero de ellos, entre "grandes blasfemias al Santo Nombre de Dios", que se tomaría «terribles venganzas cuando esto diera la vuelta", replicó el contertulio que anhelaba la muerte de Franco, al que calificó de «fartón» porque «no hacía otra cosa que matar al pueblo de hambre y dar leyes y más leyes". Tras la investigación policial se subrayó el nexo familiar que existía entre denunciante y denunciados y se demostró que las acusaciones eran una patraña urdida por resentimientos personales ${ }^{48}$. En junio de 1945, dos guardias jurados de Fábrica de Mieres, de antecedentes falangistas y ex divisionarios, acusaron a varios vecinos de Tablado, todos ellos de antecedentes marxistas, de haberles amenazado con "cortarles la cabeza por fascistas tan pronto como desapareciera este régimen". Una vez realizada la consiguiente investigación, en la que se constató la existencia de una vieja enemistad entre las partes, quedó descartado que se hubieran proferido semejantes amenazas. Por el contrario, se concluyó

46 Parte del SIP núm. 173, 26 de junio de 1945 y núm. 205, 24 de julio de 1945. Jefatura Provincial del Movimiento, 30 de noviembre de 1945.

47 Jefatura Local de Pola de Lena, 11 de julio de 1944.

48 Instancia de 8 de septiembre de 1942. Puesto de Avilés, 16 de septiembre de 1942. 
en el informe que la denuncia había sido urdida por uno de los guardas, Fernando Fernández Fernández, en venganza por haber sido condenado por "maltratar de obra" a una de las denunciadas, Felicidad Suárez 49 .

\section{LA PROPALACIÓN DE «ESPECIES INSIDIOSAS»}

La estabilidad del Régimen en la inmediata posguerra dependía, en buena medida, de la compenetración de sus principales soportes: el Ejército, la Iglesia y el Partido Único. Los tres compartían objetivos y estaban unidos por la existencia de un adversario común, pero, a pesar de ello, no siempre mantuvieron los mismos criterios. Cada vez que una desavenencia transcendía, era recibida con alborozo por los enemigos del régimen, quienes la interpretaban como un síntoma de desunión y, por tanto, de debilidad. Por ello, los más combativos se dedicaron a fomentarlas e incluso, cuando no existían, a inventarlas, difundiendo todo tipo de bulos e insidias de carácter político. Ya en enero de 1941, para cortar de raíz estas «murmuraciones, rumores y patrañas» atribuidas a «elementos rojos o simpatizantes con ellos que han quedado incrustados en nuestra Patria después de la Guerra de Liberación", el Ministerio de la Gobernación dispuso, mediante circular, que se aplicaran en estos casos las más «severas sanciones" 50.

Actuaciones de este tipo quedan confirmadas en un documento escrito en clave, titulado "pequeños apuntes diarios" y sin más firma que un "viva la República», aprehendido por la Guardia Civil en 1943. En él confesaba su anónimo autor que, "tras consultar el caso" con otras personas, el 10 de marzo de 1941 habia redactado un manifiesto de carácter falangista con el que pretendía indisponer «al elemento militar y al clero con la falange", el cual se distribuyó en Asturias, Madrid, Bilbao, Valladolid y León. Desde esta fecha consignaba el documento, casi a diario, las diversas reacciones que suscitó el texto, enviado por correo, y en el que, probablemente, se mostraba la indignación falangista por una hipotética restauración monárquica. Entre otros testimonios, se recogieron los ácidos comentarios vertidos «en la peña militar del bar Central por el Comandante Naves» y, asimismo, las manifestaciones de un comandante de

49 Parte del SIP núm. 162, 13 de junio de 1945. Gobierno Militar de Asturias, 31 de julio de 1945.

50 Ministerio de Gobernación, Política Interior, orden circular núm. 3, 20 de enero de 1941. 
infantería, que se atrevió a insinuar que los autores del escrito contaban con la ayuda del gobernador civil de Asturias. En la anotación del 30 de abril atribuyó al oficial el siguiente comentario con respecto a la citada autoridad civil: «antes de tener que pedir nada a este antimilitarista le tomo a la fuerza por los fusiles". También comentó con satisfacción que se había abierto un expediente investigador, ante el que habían declarado conspicuos falangistas como «Sánchez Sarachaga, Hoyos (el médico) y Rodrigo, jefe de Información e Investigación".

Con mayor jactancia se recogía, a continuación, que el diario Arriba, "órgano oficial del Gobierno", tuvo que salir al paso del panfleto en su edición del 11 de mayo con un editorial titulado "denunciamos al mingo", reproducido dos dias después por Proa, al que despectivamente calificaba como «hoja parroquial». En días sucesivos este periódico local se hacía eco del manifiesto, atribuyendo su autoría a agentes desestabilizadores al servicio de Inglaterra. En el comentario del 18 de mayo se deja entrever que las destituciones de Dionisio Ridruejo y de Antonio Tovar, así como los relevos de José Larraz López y Pedro Gamero del Castillo al frente del Ministerio de Hacienda y de la Secretaría General del Movimiento, no fueron ajenas a la circulación de los manifiestos. Esgrimía para ello el contenido del discurso pronunciado por José Luis Arrese al tomar posesión de la Secretaría General del Movimiento, en el que reiteraba la absoluta fidelidad de Falange al Ejército, como quedó patente en el acto de confraternidad que conjuntamente celebraron en Cuatro Vientos el 28 de mayo de 1941. Para salir al paso de los comentarios periodísticos y realizar una valoración de las destituciones, el autor del diario redactó dos réplicas que remitió por correo a destinos seleccionados de Lugo, Vigo, Orense, Pontevedra, León, Burgos, Zamora, Valladolid y Madrid. Uno de ellos se remitió al propio José Luis Arrese con una apostilla escrita en carmín rojo muy explícita: «la traición se paga con la vida».

A partir de aquí puntualizaba que se había extremado la vigilancia, sobre todo de la correspondencia, y que se habian cursado órdenes a todos los medios de comunicación para que omitan cualquier referencia al contenido de los escritos. Se comentaba, además, un nuevo editorial publicado en Arriba el 17 de junio bajo el título "servir al Estado", en el que se instaba a los falangistas a que no olvidaran tres principios canónicos de José Antonio: «silencio, abnegación y obediencia». En el resto de anotaciones, que abarcan un mes más, se hacía referencia al nuevo giro de la guerra mundial, percibida como «la última carta que nos queda para con- 
seguir el triunfo, esto es, la libertad, la justicia y el derecho a la vida". Se comentaban en tono despectivo las manifestaciones promovidas «contra Rusia" y se analizaba la posibilidad de enrolarse en la División Azul para luego cambiar de bando, pero se desechaba la idea al requerirse que los voluntarios pertenecieran a Falange y dispusieran de un certificado de ex combatiente. No obstante, como consideraba una "cobardía permanecer con las manos cruzadas" y en "vista de que por ahora no se puede trabajar» dada la intensa vigilancia, el 9 de julio decidia alcanzar la frontera portuguesa a través de Verín para, una vez fuera de España, «obrar en consecuencia» 51.

\section{EL RECHAZO DE LAS SUBSCRIPCIONES Y LAS POSTULACIONES}

Durante la guerra civil, los sublevados utilizaron diversos procedimientos para que la población no combatiente de las zonas que controlaban contribuyera económicamente a sostener el esfuerzo bélico y atender las necesidades humanas. En un ambiente de exaltación patriótica y de movilización social, fluyeron las aportaciones sin que fuera necesario imponerlas, ya fuera por afinidad ideológica, ya para dejar constancia de adhesión a las fuerzas nacionalistas o, también, para mitigar un pasado político comprometedor. Entre otras gabelas se estableció la llamada «ficha azul», con la que se recaudaban fondos para financiar, principalmente, los comedores para indigentes promovidos por Auxilio Social. Esta aportación carecía de un gravamen fijo, porque cada contribuyente negociaba con el delegado de la Obra, a tenor de su patrimonio, la cuota mensual, que generalmente oscilaba entre 1 y 10 pesetas. En teoria, el compromiso se adquiría de forma voluntaria y no existia ninguna prescripción legal que lo impusiera, pero una parte de la población lo subscribió únicamente para que sirviera de escudo frente a previsibles represalias políticas. Incluso personas "de orden y de derechas", llegaron a reconocer que habían aceptado la contribución como una forma de protección personal. Así, por ejemplo, Vicente Busto Álvarez, que había realizado importantes aportaciones económicas y había entregado sus posesiones en oro a la causa nacionalista, admitió que se le había asignado la cuota «contra su voluntad y debido a presiones y amenazas ejercidas por los delegados de Auxilio Social de Cudillero" 52. Esta coacción solapada estaba avalada por el propio Ministerio de la Gobernación, el

51 "Pequeños apuntes diarios".

52 Puesto de El Pito, 24 de enero de 1942. 
cual, mediante órdenes circulares de octubre de 1938 y julio de 1941, había facultado a los gobernadores civiles para que «apelaran al imperio de su autoridad cuando el propio convencimiento y los medios persuasivos no sean bastantes a conseguir la cooperación por todos debida a la Obra de Auxilio Social» 53.

Desaparecidas las circunstancias excepcionales de la guerra y, quizás también, atenuada en parte la capacidad intimidatoria de la organización falangista, comenzaron a apreciarse los primeros conatos de resistencia a abonar la «ficha azul». En 1941 fueron denunciados por este motivo un vecino de Cudillero, cuatro de Siero y Carreño, diecinueve de Riveras de Pravia y dieciséis de Trasona. Todos ellos arguyeron que la contribución no era obligatoria, pero los últimos citados, además, "hicieron causa común", consultaron con un abogado, presentaron un recurso contra su sanción ante el Ministerio de la Gobernación y se negaron a seguir pagando hasta que no recibieran una resolución firme sobre el carácter del tributo. Ante su actitud de obstrucción y dada su "contumacia», fueron nuevamente denunciados en julio de 1942 y, para que no cundiera el ejemplo, se les duplicó la cuantía de la sanción inicialmente impuesta. Se pretendía así castigar con especial rigor a quienes «se niegan a abonar su cuota fiados en la fuerza que suponen les da una rebeldía colectiva» 54 .

Cuando esta actitud era adoptada por “desafectos», además de pormenorizar el patrimonio del renuente, se enumeraban también los antecedentes políticos. Emilio Rodríguez, a quien se atribuía que «voceaba por las calles que el mismo Franco tendrá que venir a cobrarle", se presentaba como un «marxista destacado». Según el delegado local, durante una entrevista sostenida con el alcalde para rebajar su aportación había adoptado una postura de «intransigencia un tanto grave», había increpado al primer edil y, ante la benevolencia de la autoridad local, había golpeado reiteradamente su mesa, «insultando así mismo no solamente a la institución sino también al Régimen». Por el mismo «espíritu de gran rebeldía" rechazaban el tributo los hijos de Manuela Álvarez, de El Villar, calificados como "gentes brutísimas dadas a la mala moral de siempre", además de «grandes blasfemos, marxistas y ateos". A la misma "escue-

53 Ministerio de la Gobernación. Dirección General de Beneficencia y Obras Sociales, 5 de agosto de 1942.

54 Jefatura Provincial del Movimiento, 28 de noviembre de 1941 y 9 de julio de 1942. Gobierno Civil, 3 de diciembre de 1941. Instancia de José Muñiz Muñiz y otros, 5 de agosto de 1942. 
la marxista" se adscribían otros remisos como Celestino Martínez, los hermanos Restituto y Francisco Palicio, Manuel Álvarez Arias, Avelina Martínez y Manuel Granda García. Del primero se recordaba que habia formado parte de la "Gestora comunista de Soto del Barco", mientras que del último citado se precisaba que era un «marxista consumado de los que aún vocean" 55 .

Ahora bien, como ya hemos señalado, contra este tributo reaccionaron, con no menor hostilidad, conspicuos franquistas. Tanto el rechazo colectivo suscitado en Riberas de Arriba como el de Avilés estuvieron promovidos por dos cargos públicos, los alcaldes de barrio de Los Veneros y Trasona. De este último, José Muñiz Muñiz, se subrayaba que "venía haciendo labor para que los demás vecinos no paguen», aconsejándoles que se asesoraran jurídicamente. A pesar de que el impuesto era módico y progresivo, casi todos argumentaban que la carga les resultaba excesivamente onerosa, dadas las palmarias necesidades y privaciones del momento, lo cual solía ser refutado con rotundidad por el delegado local de la Obra. El ya citado Vicente Busto Álvarez, entre "frases injuriosas", arguyó para justificar su actitud que «no estaba dispuesto a que los chicos de Auxilio Social le comiesen lo que a él tanto trabajo le costó ganar en Cuba». Sin embargo, la Guardia Civil del Pito recordaba que en fecha reciente habia tenido "el capricho" de construirse el panteón más fastuoso del cementerio y que había «comprado en esa capital un piano para regalo y distracción de su hija». Emilio Rodríguez, del barrio de La Uz en Riberas de Pravia, se comprometió incluso a incrementar la cuantía de su ficha "si Auxilio Social daba de comer a un cuñado con cuatro hijos que tenía recogidos en su casa", lo que fue interpretado por el delegado local de la Obra como «un intento de soborno». Por su parte, José Menéndez, vecino de Manzaniella, alegó para no pagar que ya eran muchas las limosnas que repartía mensualmente. Como el tipo de gravamen era variable, con estas objeciones y protestas se pretendia obtener, generalmente, una revisión a la baja de la cuota mensual 56 .

Este rechazo solía venir acompañado de graves críticas contra la institución, mucho más aceradas que las vertidas por los opositores izquierdistas. Para el indiano de Cudillero, dada la «mala calidad y el raquitismo

55 Delegación Local de Auxilio Social de Riveras de Pravia, 26 de abril de 1941. Jefatura Provincial del Movimiento, 29 de agosto de 1941.

56 Jefatura Provincial del Movimiento, 28 de noviembre de 1941 y 14 de enero de 1942. Puesto de El Pito, 24 de enero de 1942. 
de las comidas que se daban en los comedores a los niños", era evidente que los delegados «se estaban beneficiando de parte de sus donativos". En la misma línea, el también derechista Leonardo Solis, de Fafilán, arguyó que «le sobraba el dinero, pero no para el Auxilio Social, pues está convencido de que la recaudación no es más que para cuatro fartones". Más contundente en sus imputaciones fue Faustina Buria Alonso, «derechista" de Riveras de Pravia a quien la "Horda en el pueblo había asesinado a un hijo». Ante el alcalde de la localidad manifestó que «en los comedores se mantenía a niños cuyos padres se hallaban ganando sus jornales y que (el delegado local) amparaba robos y saqueos de géneros de los comedores", insinuación que se convirtió en uno de los rumores más populares de la época. Aunque sin descartar estas insidias, otras personas de orden utilizaron pretextos de marcado carácter político. María Arbesú Grana y Lucinda Díaz fundamentaron su rechazo manifestando que en los comedores "no se mantenía más que a rojos", lo que fue corroborado por Celestino Galán García, "Camisa Vieja» y gestor del ayuntamiento de Soto del Barco, quien apostilló que también se «atendía a parásitos". De éste se precisaba con ironía en el informe del delegado local que era el único de su casa que siempre había sido del partido de orden, "pero siempre desordenado". Sin tanta animosidad, una vecina de Manzaniella se había negado a pagar su cuota tras manifestar que «Auxilio Social era cuento", mientras que en opinión de Álvaro Prendes, de Gudín, "lo de la Ficha azul ya había muerto". También se denunció por «hacer campaña» contra la Institución o por recibir con hostilidad a las cobradoras, entre otros, a Constantina Viña, a José Cuervo, a María Suárez y a Ramón García. Este último, derechista como los demás y vecino de Silvota, al parecer las recibió “con insultos y palabras soeces» 57.

Como procedían de personas influyentes de acreditada solvencia económica, estas actitudes "de boicot» eran comentadas por los integrantes de Auxilio Social con especial acritud, ya que alimentaban los rumores más insidiosos y «daban ejemplo de rebeldía a los suscriptores de inferior posición económica". Así se dejó constancia, al menos, en las denuncias presentados contra José Garcia Rodríguez y Álvaro Cuervo, dos destacados "acaudalados" de Guimarán y Candás que "siguen haciendo oídos sordos a las llamadas de nuestra Obra" 58. Molestaba particularmente que, para reforzar su posición, se prevalieran de sus inequívocos antecedentes políticos y, cuando era posible, como en el caso de

57 Jefatura Provincial del Movimiento, 29 de agosto y 28 de noviembre de 1941. Puesto de El Pito, 24 de enero de 1942.

58 Jefatura Provincial del Movimiento, 31 de marzo de 1941. 
Ramón Fernández Cotollano, de Riveras de Pravia, que esgrimieran incluso los familiares «inmolados por la Causa". No se ocultaba que en todo ello, "y en sus amistades", depositaban su confianza como salvaguarda eficaz contra multas $u$ otro tipo de sanciones. Como ejemplo se comentó el caso de María Arbesú Grana, que recurrió a sus «influencias" para que le fuera condonada una módica multa por proporcionar «comestible falto de peso». Otros menos respaldados, como Generosa Fojaco, Ramón Suárez o José y Aquilino Álvarez, todos ellos «gente de orden aunque de espíritu cerrado", se aferraban a estos precedentes para conseguir la misma impunidad 59.

Las postulaciones promovidas por Auxilio Social con los mismos fines, las cuales solían efectuarse dos domingos de cada mes, también suscitaron múltiples expresiones de malestar. La medida recaudatoria, en este caso, tenía una eficacia erga omnes, ya que todos estaban obligados a portar el distintivo no bien accedían a establecimientos de bebidas, espectáculos públicos o cualesquiera locales de diversión y esparcimiento. Como la cantidad requerida en la postulación que se realizaba cada quincena era módica, la mayoría prefería evitar complicaciones y colocarse el emblema en la solapa, pero algunos se atrevieron a dejar constancia pública de su desafección política rechazándolo. Por este motivo fue denunciado al gobernador civil en noviembre de 1941 Javier del Gallego Braña, de Lastres, quien, además de rechazar la pegatina, «llegó incluso a insultar a las camaradas encargadas de tal servicio" 60. El estupor de las autoridades ante comportamientos de este tipo solía crecer al comprobar que casi nunca se rechazaba el emblema alegando motivos económicos, ante los que podrían mostrarse sensibles. Antes al contrario, como se detalla en la denuncia presentada por la Guardia Civil de Luarca contra el marinero José Gayol Rodríguez, de 71 años, había personas que mantenían su negativa a pesar de que, como en esta ocasión, el propietario del bar lo regalaba 61 .

Estas reacciones, aunque fueran aisladas y espontáneas, casi siempre se interpretaban como un gesto de oposición política y, por tanto, se ilustraban con los antecedentes personales e ideológicos del infractor. Así, al denunciar dos militantes de la Sección Femenina de Pola de Lena que habían sido expulsadas a la calle "en malos términos" por el dueño

59 Jefatura Provincial del Movimiento, 29 de agosto de 1941.

60 A. Arias de Velasco, Jefe Provincial de FET y de las JONS, al Gobernador Civil, 12 de noviembre de 1941.

61 El Comandante del Puesto de Luarca al Gobernador Civil, 19 de noviembre de 1941. 
de un bar cuando pretendian realizar la postulación, se trajo a colación de inmediato que el denunciado, Maximino Morán López, era de «ideología socialista» y «durante la dominación roja se reunían en su establecimiento las más destacadas figuras del marxismo». Generalmente se solian magnificar los antecedentes y los términos de la ofensa recibida, como después comprobaba la Guardia Civil, para que el hecho no quedara impune. En este caso concreto, «las personas de orden» que presenciaron el altercado desmintieron el contenido de la denuncia, precisándole al comandante del puesto de Pola de Lena que el propietario se había limitado a comunicar que él ya había adquirido el distintivo para todos sus clientes. También negaron que las hubiera cogido del brazo y expulsado del local manifestando, como habían afirmado las postulantes, que «en su casa no mandaba ni el Jefe Local de Falange ni el Alcalde" 62.

La particular animosidad contra el vencido se advierte en la denuncia presentada en noviembre de 1941 contra un grupo de "chigreros" de Lada por atender a clientes que no portaban el preceptivo emblema. Sin que existiera una justificación basada en la magnitud de la infracción, se reclamó que fueran sancionados con mayor severidad Florentino Coto y Ángel González Suárez. El primero se merecía un castigo suplementario dada su «intervención durante la dominación roja, encontrarse en prisión atenuada y estar considerado como desafecto", mientras que del segundo se precisaba que se le había retirado un aparato de radio «por tener confidencia esta Delegación que reunía a personas desafectas, propagando noticias favorables a Rusia y contra Alemania e Italia»63.

Cuando los obstáculos a las cuestaciones procedían, como en los casos anteriores, de los propietarios de los locales públicos las reacciones eran más desabridas, toda vez que estos dependían de la autoridad gubernativa para ejercer sus actividades profesionales. Por «negligencia manifiesta" al permitir la entrada o servir consumiciones sin el preceptivo emblema fueron denunciados en octubre de 1941 el "Café Madrid", la "Confitería Rey» y el "Cine Argüelles», todos ellos en Cangas de Narcea ${ }^{64}$. En 1951, obviando el preceptivo cauce de la Jefatura Provincial del Movimiento, la delegada local de Auxilio Social y de la Sección Femenina de Villaviciosa se dirigió directamente al gobernador civil para denunciar

62 Denuncia de América González y Leonor Fernández, sin fecha. El Jefe Provincial del Movimiento al Gobernadó Civil de la Provincia, 24 de enero de 1942. El Comandante del Puesto de Pola de Llena, 2 de íebrero de 1942.

63 Jefatura Provincial del Movimiento, 6 de diciembre de 1941. El Gobernador Civil, 13 de diciembre de 1941.

64 Guardia Civil, Fuerza Concentrada, 14 de octubre de 1941. 
que el dueño del «Teatro Riera» permitía que se accediera a su sala de espectáculos sin el correspondiente emblema. En el oficio se precisaba que Laureano Riera García retiraba muy pocos emblemas de la delegación -solamente 150 a pesar de que en días festivos su local era frecuentado por más de medio millar de personas-, que de ellos sólo colocaba 40 y que, además, devolvía el resto con mucho retraso. Por todos estos agravios se concluía que el «desaprensivo industrial se permite el lujo de sabotear descaradamente la humanitaria labor que con los ingresos de las cuestaciones desarrolla esta institución Nacional-Sindicalista» 65.

Aunque en la ocasión precedente no se pueda interpretar la actitud del empresario como una muestra de resistencia política, generalmente sí se consideraba que quienes adoptaban esta actitud esgrimian argumentos ideológicos, especialmente cuando la postulación se realizaba en nombre de las organizaciones más representativas del Movimiento. Por este motivo se produjo en 1948, en las inmediaciones del campo de fútbol del Real Avilés, un incidente que a punto estuvo de acabar en pelea callejera. Al ser requerido Antolín Muñiz García para que se proveyera de un distintivo del Frente de Juventudes, éste manifestó que «no daba un céntimo» para la citada organización, aunque en la Comisaría de Policía puntualizó que se había negado por creer que no estaba obligado a ello. Los falangistas incluyeron en la denuncia a varios directivos del Real Avilés, a quienes acusaron de boicotear las postulaciones y sembrar dudas sobre su obligatoriedad. No obstante, tras la investigación policial se demostró que eran dos acreditados falangistas - uno de ellos había sido asesor comarcal de cultura del Frente de Juventudes-, y que únicamente habían terciado para que la reyerta no bloqueara la puerta principal de acceso al estadio. Del denunciado se destacaba su «filiación izquierdista», aunque sin más precisiones 66 .

\section{MOTINES DE SUBSISTENCIA}

Las expresiones más airadas y desafiantes de protesta popular se suscitaron para denunciar las misérrimas condiciones de existencia que tuvieron que afrontar la mayor parte de los trabajadores. Estas reacciones, como en los casos anteriores, también solían tener un carácter espontá-

65 La delegada local de Auxilio Social y de la Sección Femenina de Villaviciosa al Gobernador Civil, 1 de mayo de 1951.

66 Jefatura del Frente de Juventudes del Distrito Universitario de Oviedo, 9 de octubre de 1948. Comisaría del Cuerpo General de Policia de Avilés, 21 de octubre de 1948. 
neo e individual. En octubre de 1941, el año de mayor escasez según la memoria colectiva, Araceli Fernández Álvarez fue denunciada por el jefe de Falange de Lugones, José Rivas Sánchez, por rogar a Dios en el tranvía que tirara «una bomba y los aplastara a todos», lo que fue interpretado como "frase injuriosa contra el nuevo Estado". En su descargo matizó que el artefacto explosivo no lo reclamaba para las autoridades sino para ella y su familia, que se encontraban en situación calamitosa, ya que "con esto de la Nueva España nos dejan sin leche, ni pan» 67. Sin ir más lejos el mismo año, aunque en el mes de abril, un vecino de Nueva de Llanes denunció a Ramón Díaz del Río por haber criticado los abusos de las autoridades en materia de abastos y haber reconocido en público que «la gente se moría de hambre». En concreto, había calificado de «atropello" que la Benemérita hubiera decomisado recientemente $40 \mathrm{~kg}$. de maíz «por no llevar la guía de circulación» 68. Al no mejorar los suministros alimenticios con el paso del tiempo, las reacciones populares se tornaron, si cabe, más amargas e iracundas. En julio de 1943, Galo Argüelles Ortíz bramó indignado en un chigre de Mieres que no había pan, que estaba dispuesto a ir a León para comprarlo y, sin tapujos, consumirlo luego en plena calle, añadiendo en tono amenazante que "se lo metería por el focicu" a quien le quisiera hacer un reproche por su actitud. También manifestó que anhelaba el momento en el que entraran los ingleses y los norteamericanos en Gijón para que pusieran fin a un régimen que calificó de «famélicos y sinvergüenzas". En el informe policial se explicaba que el indignado mierense había sido de los primeros expulsados de Falange, donde ingresó no bien concluyó «la liberación de Asturias», por sus antecedentes izquierdistas y que, además, estaba resentido «por habérsele fusilado a un cuñado por su actuación durante el periodo rojo» 69.

En estas circunstancias, la gente se solía solidarizar con el modesto estraperlista que se resistía a perecer de hambre y reaccionaba con hostilidad cada vez que los agentes de la autoridad se incautaban de los bienes adquiridos con esfuerzo y a precios abusivos en el mercado negro. Dada la incapacidad de las autoridades para proporcionar mediante el racionamiento y a precios tasados lo imprescindible para vivir, la «moral» popular interpretaba que cada cual estaba legitimado para asegurarse su subsistencia con los medios que tuviera a su alcance, con independencia de que estos fueran legales o ilegales. Para eilos, en puridad, no se delinquía, ya que el derecho "natural» a la supervivencia primaba sobre la norma hu-

67 Puesto de Lugones, 30 de octubre de 1941.

68 El Puesto de la Nusva, 14 de abril de 1941.

69 Cuerpo General de Policia. Inspección de Mieres, 18 de julio de 1943. 
mana 70 . A través de múltiples indicios se palpa un generalizado ambiente de repulsa e indignación, que no derivó en respuestas más airadas únicamente por el temor que infundían las autoridades. La imaginación popular, en aquellos años, tuvo que alumbrar nuevas formas de protesta, algunas inspiradas en métodos tradicionales, para mostrar su descontento, como nos recuerdan protagonistas y testigos. Arcadio Iglesias Montes evoca en sus memorias que no era infrecuente que aparecieran en la puerta de algunos cementerios carteles con una premonitoria leyenda: «Para abril todos aquí; el que no quiera esperar cola que venga ahora». El texto se completaba con un pollino dibujado del que pendía el siguiente interrogante, no menos expresivo: “¿Después de muerto el burro, qué?» 71.

Mientras que ante estos desahogos se actuaba con cierta condescendencia, porque la escasez de alimentos era palmaria, las medidas represivas se aplicaban con toda severidad cuando las manifestaciones de disgusto adquirian mayores proporciones y, sobre todo, transcendían a la opinión pública. No sin fundamento se temía que estas protestas colectivas fueran utilizadas por los adversarios para alentar la resistencia popular y difundir en el exterior que el Régimen sufría una fuerte contestación interna. Con imprecisiones, tanto los comunistas como los socialistas constataron la existencia de varias manifestaciones y protestas protagonizadas por mujeres para quejarse de la anormalidad en el suministro de productos básicos, criticar la escasez de lo repartido o denunciar su pésima calidad. Por estos motivos se produjeron en 1944, según estas fuentes, "amotinamientos" en Sama y la Felguera y, dos años después, en Gijón. Parece ser que en la villa marítima se impuso una multa a 17 mujeres por denunciar favoritismos en el reparto de leche ${ }^{72}$. También en 1946 , en el mes de agosto, sitúa Jesús Izcaray un plante de los mineros en el interior de la mina la Piquera de Turón para reclamar un mayor racionamiento 73. Por las mismas fechas, en fin, se concentraron ante el ayuntamiento de Mieres un grupo de mujeres con la misma demanda, movilización que años después sería comentada autocríticamente por un

70 Servicio de Información de la DGS. Boletín Decenal núm. 19, Oviedo, 10 de julio de 1943.

71 Arcadio lgLESIAS MONTES: 50 años de militancia comunista (memorias para mi nieta). Oviedo, 1997, pág. 32.

72 Reconquista de España, núm. 43, abril de 1945. Citado por César TCACH y Carmen REYES: Clandestinidad y exilio. Reorganización del sindicato socialista, 1939-1953. Madrid, 1986, pág. 93. Mundo Obrero, 8 de mayo de 1946 y Ángel Álvarez, «Luchas en Asturias». Citado por Rubén Vega Garcia y Begoña Serrano Ortega: Clandestinidad, represión y lucha política. El movimiento obrero en Gijón bajo el franquismo (1937-1962). Gijón, 1998, pág. 152. De estos autores adoptamos el término «motines de subsistencia».

73 Jesús Izcaray: Héroes de España. Casto Garcia Roza. París, 1948, pág. 132-135. 
grupo de militantes comunistas para concluir que, en esos años, se había "subestimado" la combatividad popular y se había "descuidado el trabajo con las masas» 74 .

Aunque estas informaciones adolecen de precisión y, generalmente, solían estar magnificadas, no por ello deben ser menospreciadas. Se hacen eco del lógico malestar existente por el deficiente racionamiento de la población y reflejan conatos de rebeldía que están plenamente confirmados por otras fuentes menos cuestionables. En un boletín decenal de la Dirección General de Seguridad de julio de 1943 se reconocía sin tapujos "el disgusto general» de la población, especialmente cuando se reducía o suspendía el suministro de pan, ya que este producto "solía tapar la gran necesidad que se experimenta de otros artículos". En este informe no se ocultaba la indignada reacción de los vecinos de Villaviciosa al constatar que los puestos del mercado semanal estaban repletos de panecillos que se vendían a "una peseta veinticinco céntimos» mientras que «la población se encontraba sin racionar». Tampoco se omitía que en las zonas mineras las mujeres cuyos maridos se dedicaban a otras actividades "protestaban públicamente" por el trato preferente que recibían los mineros a través de los economatos. Aunque se admitía que estos también acusaban un alarmante desabastecimiento y que proporcionaban mucho menos de lo establecido, al menos sí garantizaban el suministro de pan, mientras que el resto de trabajadores «carecen de este artículo con el que reparar sus tan quebrantadas fuerzas" 75 .

El deficiente abastecimiento y la pésima calidad de los productos que se despachaban queda confirmado por la actitud que adoptaron el 12 de mayo de 1947 un grupo de mujeres ante el economato de Collanzo de la Sociedad Hullera Española. En esta fecha, encabezadas por catorce vecinas de El Pedroso, Collanzo, Santa Cruz y Oriella, protagonizaron un plante colectivo ante el citado establecimiento. Adoptaron esta actitud para exigir el inmediato traslado del encargado del despacho, Secundino Velasco Álvarez, a quien acusaron de tratarlas de forma despótica y de alterar los pesos y medidas para sisarles parte del racionamiento. Según el atestado de Pedro Gómez Rivas, comandante jefe de la Zona Sur de Asturias, las mujeres se comprometieron a mantener su negativa hasta que su reclamación fuera satisfecha. Evidenciaron con ello, en opinión de la Guardia Civil de Caborana, «una rebeldía que en ningún caso debe quedar sin el castigo correspondiente para ejemplo de los que sueñan

74 “Experiencias sobre $\in I$ trabajo de masas en Asturias", enero de 1955. Archivo del PCE.

75 Boletín decenal de la DGS, Oviedo, 10 de julio de 1943. 
que con actos de esta naturaleza pueda minarse poco a poco el principio de Autoridad, evitando con ello aspiraciones posteriores para realizar otros o parecidos como el presente". Con todo, se matizaba que unas habían actuado por «apatía o cobardía», mientras que otras, la mayoría, "con verdadera satisfacción porque ello suponía buscar complicaciones al buen orden que debe reinar bajo el mando de nuestro Caudillo". En todo caso - se concluía- no se podía condescender porque con estas acciones se pretendía "pulsar el ambiente para ulteriores efectos de aspiraciones de enemigos del Régimen (sic)» 76.

Ante la mala calidad de los alimentos y cada vez que se reducía la ración de los productos básicos, la indignación popular se expresaba mediante críticas acerbas y suspicaces comentarios dirigidos contra las autoridades locales. La gente corriente estaba convencida de que los alimentos que se le escatimaban estaban siendo desviados por el personal de abastos hacia el mercado negro para obtener con su venta pingües beneficios. Ello favorecía que se diera pábulo a todo tipo de rumores sobre las causas de la escasez y, además, que se mirara con recelo a quienes no pasaban estrecheces, sobre todo si se trataba de funcionarios públicos, autoridades 0 , en todo caso, personas influyentes. Así pues, al decretarse en Avilés el 12 de julio de 1947 una rebaja en 25 gramos de la ración de pan, inmediatamente los vecinos atribuyeron la medida a una maquinación del alcalde para suplir la ausencia de unos sacos de harina que habían desaparecido. Como reflejo del generalizado ambiente de indignación que existía por la merma, se dejaba constancia en un informe policial del testimonio de «una señora» manifestando que «esto es la mayor desvergüenza y latrocinio que se ha podido imaginar, todo es estraperlo, y ahora que han ganado las elecciones ya no importa que la gente se muera de hambre". Comentarios de este tipo, realizado en esta ocasión en la plataforma de un tranvía, se repetían todos los días "con la máxima frecuencia en tabernas, cafés, en la calle y por personas de todas las categorías sociales" 77 .

\section{CONCLUSIÓN}

76 El Comandante Jefe, 17 de mayo de 1947. Puesto de Caborana, 21 de mayo de 1947. El Gobierno Militar de Asturias, 23 de mayo de 1947.

77 Servicio de Información de la DGS, Oviedo, 14 de julio de 1947. 
El franquismo no se sintió nunca amenazado por estas expresiones individuales y espontáneas de resistencia, pero las sometió a estrecha vigilancia y las reprimió. Traslucen el rechazo del derrotado al modelo político dominante y, asimismo, el malestar social provocado por las penurias cotidianas. Aun en su aleatoriedad y variedad, tanto en la forma como en el fondo, reflejan los vaivenes del Régimen. Mientras la violencia represiva se desplegó con toda intensidad -en Asturias entre 1937 y 1940-, este tipo de expresiones de rechazo quedaron confinadas al ámbito más íntimo y privado. El comienzo de la guerra mundial y la subalterna implicación de España, unido a las primeras excarcelaciones de los condenados, devolvieron la esperanza a algunos desafectos, propiciando que se adoptaran posturas más desafiantes. Los actos de hostilidad se incrementaron a partir de 1943 y alcanzaron su apogeo en 1945, coincidiendo con el triunfo aliado. En este umbral se mantuvieron un breve lapso de tiempo, pero terminaron languideciendo al descartarse que el Régimen fuera derribado desde el exterior. Como hemos visto, fueron protagonizados por personas «desafectas" o, más excepcionalmente, por quienes estaban clasificados como «indiferentes". Sin embargo, también mostraron su hostilidad simpatizantes del Movimiento, unas veces molestos por algún abuso de autoridad y otras veces para rechazar las reiteradas punciones económicas a las que estaba sometida la población. En todo caso, estas reacciones no tienen entidad suficiente para concluir que reflejan la existencia de una cultura popular de resistencia al franquismo, pero al menos confirman que la actitud de la población no fue tan resignada como se ha afirmado. 